Journal of Applied Pharmaceutical Science Vol. 6 (02), pp. 016-021, February, 2016

Available online at http://www.japsonline.com

DOI: $10.7324 /$ JAPS.2016.60203

ISSN 2231-3354 (cc) EY-NC-SA

\title{
Teachers' Knowledge, Beliefs and Practices of Breast Self-Examination in a City of Philippine: A Most Cost-Effective Tool for Early Detection of Breast Cancer
}

\author{
Roy Rillera Marzo, Abdus Salam* \\ Department of Medical Education, Universiti Kebangsaan Malaysia, Kuala Lumpur, Malaysia.
}

\begin{tabular}{l} 
ARTICLE INFO \\
\hline Article history: \\
Received on: $31 / 10 / 2015$ \\
Revised on: $22 / 11 / 2015$ \\
Accepted on: $16 / 12 / 2015$ \\
Available online: $27 / 02 / 2016$ \\
\hline Key words: \\
Breast, self-examination, \\
cost-effective-screening-tool, \\
knowledge, beliefs, practices.
\end{tabular}

\section{INTRODUCTION}

Breast cancer is the most prevalent cancer in women worldwide (Adibi et al., 2015; Puri et al., 2009). It is estimated that $31 \%$ of cancers among women are due to breast cancer and it accounts $19 \%$ of deaths among women due to cancer (Jemal et al., 2005). There are about 1.2 million breast cancer cases worldwide and globally every 3 minutes a woman is diagnosed with breast cancer amounting to 1 million annually (Parkin et al., 2001). The incidence could go up by $50 \%$ i.e. 1.5 million by 2020 as reported by world cancer in 2008 (Parkin et al., 2005). The three recommended screening methods for breast cancer are breast self-examination (BSE), clinical breast examination (CBE), and mammography. Among these methods, mammography is the method of choice. However, owing to the high cost, its use is limited in the developing world (Devi et al.,

* Corresponding Author

Abdus Salam, Medical Education Department, Faculty of Medicine,

Universiti Kebangsaan Malaysia (National University of Malaysia),

Kuala Lumpur, Malaysia.Email:abdussalam.dr@gmail.com
1998). Clinical breast examination performed by a physician is also expensive. A combination of CBE and mammography is used frequently, although most women worldwide are not able to undergo regular CBE and mammography because of high expenses and limited availability, especially in third world countries like Philippines. Under these circumstances BSE is an appropriate, convenient and cost effective method that can be done by every woman themselves with little training (Rutledge et al., 2001). Most of the early breast tumors are self-discovered and that the majority of early self-discoveries are by BSE performers (Smith et al., 1980). Breast cancer patient's retrospective self-reports showed that there is a positive association between performance of the BSE and early detection of breast cancer (Philip et al., 1986; Sharma et al., 2013). The Canadian Cancer Society (CCS, 2005) and the American Cancer Society (ACS, 2005) continue to advise all women over 20 years old to perform regular BSE. By these means, women become familiar with the normal appearance and feel of their breasts and are better able to recognize changes and report them to their doctor for further professional evaluation (Anderson et al., 2003). 
Women in Philippine are facing the highest risk of breast cancer in Southeast Asia that continues to rise by as much as 5 percent annually. Statistics from Philippine Cancer Society in 2005 revealed that $25 \%$ of the female population in the country was suffering from breast cancer. There is a $10 \%$ risk of getting the disease to every Philippine-woman and some 6,360 breast cancer patients die each year in the country, making it the leading cause of death among Philippine women (Alegre and Ramo, 2007). Therefore, screening for early detection and diagnosis of breast cancer is very important.

School teachers play an important and unique role in health education by helping young people to develop healthy practices including BSE. Through health education in school, students are able to gain an understanding and appreciation of healthy lifestyles that promote lifelong wellbeing. There are various studies that breast cancer awareness profile at community level is largely unrepresented. The objectives of this paper is to address the knowledge, beliefs and practices of BSE among the teachers in a city of Philippine aimed to plan future interventions in this field.

\section{MATERIALS AND METHODS}

\section{Study Design and Subjects}

This was an observational cross-sectional study conducted on BSE among the teachers of primary, secondary, and tertiary schools from private and public settings in Baguio City, Philippine. The study was carried out during the periods of August and September 2009. Subjects were 450 teachers, selected randomly from different levels of schools in Baguio City, Philippine.

\section{Instrument}

The questionnaire was designed keeping consistency with the relevant literatures (Budden, 1999; Odusanya and Tayo, 2001; Demirkiran et al., 2007) and then piloted. The questionnaire was divided into four sections: socio-demographic, knowledge, beliefs, and practices. Socio-demographic section included information about participants' age, sex, marital status, level of teaching, years of teaching experience and family history of breast cancer. Knowledge section included questions on BSE awareness such as, who should perform BSE, when BSE should be started, positioning and techniques used, frequency and timing of BSE in relation to menstrual cycle. Beliefs section was determined using 'Health Belief Model' consisted of statements rated using a fivepoint Likert scale ranging from 1 (strongly disagree) to 5 (strongly agree).

The belief statements were about: Perceived confidence in performing BSE, motivation or stimulus to accept the process, susceptibility and seriousness of the disease, BSE-benefits and BSE-barrier (Champion and Scott, 1997; Champion, 1995; Champion, 1993). The practice section included questions on participants' BSE practices such as: whether they had performed BSE previously and, if so, the age at which they began to perform
BSE; the most important factor that caused them to perform BSE; the frequency of performing BSE in the prior 12 months; the time at which they performed BSE in relation to menstrual cycle; and the positioning and techniques used. If participants did not perform BSE, they were asked to provide reasons of not perform.

To investigate knowledge and practice questions concerning BSE position, techniques, frequency and timing for performing BSE, the following operational definitions were made.

\section{Position}

The position of BSE was considered correct if the participants performed BSE in both standing in front of the mirror and supine positions. If answers were recorded as BSE performed in only standing or supine position, they were considered incorrect.

\section{Technique}

The correct answer regarding techniques for conducting BSE was "inspection and palpation (by using the pads of the middle three fingers of one hand without removing the fingers from the breast, in circular motions)," If the answer was one of either inspection or palpation, it was considered to be incorrect.

\section{Frequency}

If the answer was once a month, it was considered to be correct.

\section{Timing for conducting breast self-examination}

The correct answer was "within two days after the end of the cycle" for those with regular menstrual periods and "on a specific day every month" for those with irregular or no menstruation.

\section{Data Collection and Analysis}

Data was collected by administering the questionnaire among the participants through institutional head. Before administering questionnaire, informed consent was obtained from all participants and was told all information would be kept confidential. After administration, the questionnaire was collected, compiled and analyzed using SPSS. The results were then expressed in terms of number and percentage distribution.

\section{Results}

Of 450 distributed questionnaires, 369 teachers returned the filled in questionnaire, but 52 questionnaires were excluded due to incomplete data. As such 317 questionnaires were analyzed giving a response rate of $70 \%$. Table-1 explored the sociodemographic characteristics where mean age of the participants was 40.77 with a range from 22-64 years. Among 317 teachers, $14 \%$ were male and $86 \%$ were female and most of the respondents $(72 \%)$ were married. Majority teachers (50\%) were from elementary level school, while $42 \%$ from high school and $8 \%$ from 
tertiary level schools. Thirty percent teachers possessed 11-20 years of teaching experiences. Somehow $77-87 \%$ teachers were aware of BSE while $14 \%$ had history of breast cancer in their families.

Table 1: Socio-demographic characteristics of respondents, $n=317$.

\begin{tabular}{|c|c|c|c|}
\hline $\begin{array}{c}\text { Socio-demographic } \\
\text { characteristics of study } \\
\text { participants }\end{array}$ & & $\mathbf{n}$ & $\%$ \\
\hline \multirow{5}{*}{ Age } & $<30$ & 62 & 19.56 \\
\hline & $30-39$ & 100 & 31.55 \\
\hline & $40-49$ & 82 & 25.87 \\
\hline & $50-59$ & 51 & 16.09 \\
\hline & $>60$ & 22 & 6.94 \\
\hline \multirow{2}{*}{ Sex } & Male & 45 & 14.2 \\
\hline & Female & 272 & 85.8 \\
\hline \multirow{4}{*}{ Marital status } & Single & 67 & 21.1 \\
\hline & Married & 228 & 71.9 \\
\hline & Separated & 12 & 3.8 \\
\hline & Widow & 10 & 3.2 \\
\hline \multirow{3}{*}{ Level of school at teaching } & Elementary level & 158 & 49.8 \\
\hline & High School level & 133 & 42 \\
\hline & College level & 26 & 8.2 \\
\hline \multirow{4}{*}{ Teaching experience in years } & $0-5$ & 74 & 23.3 \\
\hline & $6-10$ & 72 & 22.7 \\
\hline & $11-20$ & 94 & 29.7 \\
\hline & $>20$ & 77 & 24.3 \\
\hline \multirow{2}{*}{ Family history of breast cancer } & Yes & 43 & 13.6 \\
\hline & No & 274 & 86.4 \\
\hline \multirow{2}{*}{$\begin{array}{l}\text { Heard about breast self- } \\
\text { examination }\end{array}$} & Yes & 276 & 87.1 \\
\hline & No & 41 & 12.9 \\
\hline \multirow{2}{*}{$\begin{array}{l}\text { Any information about breast } \\
\text { self-examination }\end{array}$} & Yes & 245 & 77.3 \\
\hline & No & 72 & 22.7 \\
\hline
\end{tabular}

Table 2: Knowledge related to BSE among the teachers, $n=317$.

\begin{tabular}{|c|c|c|}
\hline \multirow[t]{2}{*}{ Knowledge related to $\mathrm{BSE}$} & \multicolumn{2}{|c|}{$\begin{array}{l}\text { Answered } \\
\text { correctly }\end{array}$} \\
\hline & n & $\%$ \\
\hline Do both sex people should perform BSE? & 172 & 54 \\
\hline Age at performance of BSE should be started & 223 & 70 \\
\hline Frequency of performance of BSE & 189 & 60 \\
\hline $\begin{array}{l}\text { Time of BSE performance in women with regular } \\
\text { menstrual cycle (within two days after menstruation) }\end{array}$ & 79 & 25 \\
\hline $\begin{array}{l}\text { Time of BSE performance in women with irregular } \\
\text { menstrual cycle (at a specific day each month) }\end{array}$ & 123 & 39 \\
\hline $\begin{array}{l}\text { Position of BSE performance should done (standing } \\
\text { in front of a mirror and lying down) }\end{array}$ & 143 & 45 \\
\hline $\begin{array}{l}\text { Technique of BSE performance (inspection and } \\
\text { palpation) }\end{array}$ & 221 & 70 \\
\hline
\end{tabular}

Teachers' knowledge on BSE as shown in Table-2 revealed that $54 \%$ of the participants knew both male and female should perform BSE, 70\% knew correct age to start BSE and 60\% knew that it should be done regularly at every month. However, knowledge about BSE timing in relation to menstrual cycle is poor $(25-39 \%)$.

Furthermore, only $45 \%$ participants knew correct position of BSE although $70 \%$ knew correct technique, that it should be conducted by inspection and palpation. Teachers' perceived beliefs towards BSE (Table-3) showed only $33 \%$ of the teachers were confident in performing BSE correctly and 65\% were motivated to accept the process of BSE. Only a small percentage $(9 \%)$ of respondents believes that they were susceptible to develop breast cancer. The table also revealed that $50 \%$ participant perceived the benefit of BSE while two third of the participants did not understand the seriousness of the disease. Table- 4 reflected that $73 \%$ participants practiced BSE. Of 232 practiced participants, $92 \%$ started BSE practices after the age of 19 and only $17 \%$ practiced BSE regularly with $10-12$ times in the past 12 months.

Among the 50\% BSE practiced participants with correct technique and $45 \%$ with correct position, only $24 \%$ participants practiced BSE at the correct time relating to their menstrual cycles (Table-5)

Table 3: Teachers' perceived beliefs towards BSE and breast cancer, $n=317$.

\begin{tabular}{|c|c|c|c|c|c|c|}
\hline \multirow{2}{*}{ Perceived beliefs } & \multicolumn{2}{|c|}{ Disagree } & \multicolumn{2}{|c|}{ Not sure } & \multicolumn{2}{|c|}{ Agree } \\
\hline & $\mathbf{n}$ & $\%$ & $\mathbf{n}$ & $\%$ & $\mathbf{n}$ & $\%$ \\
\hline $\begin{array}{l}\text { Confidence in ability to } \\
\text { perform BSE }\end{array}$ & 89 & 28 & 122 & 39 & 106 & 33 \\
\hline $\begin{array}{l}\text { Motivation to accept the BSE } \\
\text { process }\end{array}$ & 28 & 9 & 83 & 26 & 206 & 65 \\
\hline $\begin{array}{l}\text { Susceptibility to develop } \\
\text { breast cancer }\end{array}$ & 196 & 61 & 97 & 30 & 29 & 9 \\
\hline Seriousness of breast cancer & 95 & 30 & 119 & 38 & 103 & 32 \\
\hline BSE-benefits & 32 & 10 & 128 & 40 & 157 & 50 \\
\hline BSE-barrier & 191 & 60 & 90 & 29 & 36 & 11 \\
\hline
\end{tabular}

Table 4: Distribution of participants BSE practice, $n=317$.

\begin{tabular}{lcc}
\hline BSE practice & $\mathbf{n}$ & \% \\
\hline Practiced & 232 & 73 \\
Not practiced & 85 & 27 \\
Total & 317 & 100 \\
\hline
\end{tabular}

Table 5: Distribution of teachers' BSE practiced performances, $\mathrm{n}=232$.

\begin{tabular}{|c|c|c|c|}
\hline BSE practiced performances & Practices & $\mathbf{n}$ & $\%$ \\
\hline \multirow[t]{2}{*}{ Age at BSE practice started } & Before age 19 & 19 & 8 \\
\hline & After age 19 & 213 & 92 \\
\hline \multirow{3}{*}{$\begin{array}{l}\text { Frequency of BSE practiced in the } \\
\text { past } 12 \text { months }\end{array}$} & $1-3$ times & 143 & 62 \\
\hline & 4-6 times & 49 & 21 \\
\hline & 10-12 times & 40 & 17 \\
\hline \multirow{2}{*}{$\begin{array}{l}\text { Timing of BSE practiced in relation } \\
\text { to period of menstrual cycle }\end{array}$} & Correct & 55 & 24 \\
\hline & Incorrect & 177 & 76 \\
\hline \multirow{2}{*}{$\begin{array}{l}\text { Positioning of BSE practiced } \\
\text { (Correct when done by standing in } \\
\text { front of a mirror and lying down) }\end{array}$} & Correct & 104 & 45 \\
\hline & Incorrect & 128 & 55 \\
\hline \multirow{2}{*}{$\begin{array}{l}\text { Technique of BSE practiced } \\
\text { (Correct when done by use of } \\
\text { inspection and palpation } \\
\text { techniques) }\end{array}$} & Correct & 115 & 50 \\
\hline & Incorrect & 117 & 50 \\
\hline
\end{tabular}

Factors influencing practice of BSE and reasons of not practicing BSE are shown in Table-6. Fear of breast cancer was the most important factor that leads them to practice BSE $(67 \%)$, followed by training or learned from the school $(62 \%)$, recommendation by both physician and media influence 54\%, advice of a health worker (49\%) and encouraged by a breast cancer victim $(47 \%)$.

On the other hand, the most important reason for not practicing BSE was not knowing how to perform it (82\%), followed by the absence of problems in the breast (67\%), fear of finding a mass $(55 \%)$ and thinking it too difficult to perform BSE $(41 \%)$. 
Table 6: showed distribution of factors influencing practice of BSE and reasons of not practicing BSE, n-317.

\begin{tabular}{|c|c|c|c|c|c|}
\hline Factor influenced BSE practice, $n=232$ & $\mathbf{n}$ & $\%$ & Reasons for not practiced BSE, $n=85$ & $\mathbf{n}$ & $\%$ \\
\hline Fear of breast cancer & 156 & 67 & Do not know how to perform BSE & 70 & 82 \\
\hline Learned from the school & 143 & 62 & Having no problems in the breasts & 57 & 67 \\
\hline Physician recommendation & 126 & 54 & Fear of finding a mass & 47 & 55 \\
\hline Media influence & 126 & 54 & Thinking it is too difficult & 35 & 41 \\
\hline Advice of a health worker & 114 & 49 & Lack of time & 26 & 31 \\
\hline Encouraged by a breast cancer victim & 108 & 47 & Forgetting & 25 & 29 \\
\hline Breast pain & 62 & 27 & Finding it unnecessary & 24 & 28 \\
\hline Family history of breast cancer & 38 & 16 & Not knowing its importance & 2 & 24 \\
\hline Peer support & 32 & 14 & Reluctance & 12 & 14 \\
\hline Feeling of a mass & 31 & 14 & Shamefulness & 7 & 8 \\
\hline Encouraged by a friend & 26 & 11 & & & \\
\hline Nipple discharge & 16 & 7 & & & \\
\hline
\end{tabular}

\section{DISCUSSION}

The current study was an in-depth evaluation of participants' BSE knowledge, beliefs and practices. Thirty percent respondents possessed teaching experience of 11-20 years, $24 \%$ more than 20 years, $23 \%$ possessed 6-10 years of experiences in teaching with $50 \%$ elementary level, $42 \%$ high school level and $8 \%$ in college level where married respondents were $72 \%$ (Table1). Study participants found to have a good knowledge in regard to who should perform BSE, age to start BSE, frequency and techniques of BSE. However, participants' knowledge on timing of performing $\mathrm{BSE}$ in relation to regular and irregular menstruation and position of doing BSE was very low (Table-2). Previous studies also showed that there is a lack of good knowledge regarding timing of performing BSE and position to perform BSE. In one study only $17 \%$ of participants correctly identified the recommended time for BSE (Budden, 1999). Agboola et al. (2009) showed that the correct timing of BSE in women with regular and irregular menstrual cycle is below average (Agboola et al., 2009). Only $13.7 \%$ of the respondents know the correct timing to conduct the BSE (Yakubu et al., 2014). However, Demirkiran et al.,(2007) showed that $81.5 \%$ of the nurses and $45.1 \%$ of the teachers knew the correct timing which was much higher than the other studies, but regarding the position, they showed only $16 \%$ nurses and $9 \%$ teachers correctly answered regarding position of BSE (Demirkiran et al., 2007). Regarding the technique of BSE, our study revealed that teachers had good knowledge while Demirkiran et al. (2007) reported that none of the participants answered the question about technique for BSE correctly.

A good number of participants (87\%) heard about BSE in our study, which represents that participants are well aware about BSE. Study among staff nurses in Ebonyi State University Teaching Hospital showed $92.9 \%$ of them were found to have heard of BSE (Agwu et al., 2007), which is almost similar to our findings. On the contrary, study in Saudi Arabia reported only $30.3 \%$ of the participants have heard about BSE (Montazeri et al., 2008; Rizwan and Saadullah, 2009).

Regarding teachers' belief on BSE, this present study showed their perceived belief towards confidence in doing BSE and belief on susceptibility and seriousness of the disease was poor. However, half of the teachers agreed with its beneficial role in the early diagnosis of breast cancer (Table-3). This is also reflected in the practice performance rate of BSE where $73 \%$ teachers found to have practiced BSE (Table-4). Earlier studies have shown that women paid more importance to breast cancer and believe BSE should be performed regularly; however, the same subjects did not believe they were at risk for breast cancer (Budden, 1999; Odusanya and Tayo, 2001).

This is similar to this present study where more than half of the teachers $(61 \%)$ did not think they were at susceptible to develop breast cancer (Table-3). Jarvandi et al. (2002) found that most teachers feel themselves at risk of developing breast cancer that led them to perform BSE routinely (Jarvandi et al., 2002).

Demirkiran et al. (2007) reported that teachers have positive attitudes towards BSE; they were convinced to its value for early diagnosis of breast cancer and also noted that $42.5 \%$ were self-confident about performing BSE while the present study revealed only $33 \%$ teachers were confident in their ability to perform BSE correctly.

In the present study, a very good number (92\%) of teachers start practicing BSE at younger ages, although their frequency, timing and technique were poor (Table-5) compared to their knowledge. This implies that they do not practice what they know. In one study, about one third of practicing women performed six or less times correctly out of 12 times in a year and only $15.6 \%$ performed 11 times in a year, and none performed all the times correctly (Al-Azmy et al., 2013). Another study on female healthcare workers reported that more than $70 \%$ of the subjects had the knowledge of BSE and also strongly believed in its beneficial effects, but only $6 \%$ of them performed BSE regularly (Haji-Mahmoodi et al., 2002).

Our study reported that only $17 \%$ teachers practiced BSE 10-12 times and 21\% practiced 4-6 times in a year while $45 \%$ and $50 \%$ teachers practiced BSE with correct position and correct technique (Table-5).

It is reported that the ratio of practicing BSE is low in teachers (Jarvandi et al., 2002). Nurses presented a BSE practice ratio between $72.1 \%$ and $93 \%$, increasing with age (Chong et al., 2002). Study showed that students at nursing and midwifery schools start performing BSE at younger ages, but the percentages of those performing BSE regularly and at the correct time in relation to their menstrual cycle are very low with a ranged from 
$11 \%-46 \%$ (Budden, 1999).

Women health is deeply linked with the health of others (Tazhibi et al., 2014). One of the important finding in our study is that, $82 \%$ respondents did not perform BSE due to not knowing how to do BSE (Table-6). Previous studies also showed that the most common reasons for not doing BSE is lack of knowledge (Jarvandi, 2002). The world, especially the developing countries are faced with a wide variety of health-related challenges (Feyzabadi et al., 2015).

Cancer care has become a global health priority (Zisun Kim et al., 2012) and breast cancer is the most common cancer among women (Karimian et al., 2010). Medicine cannot cure all diseases (Jafari et al., 2015) and it is evidenced that BSE benefits women to detect any changes in their breasts as early as possible (Doshi et al., 2012).

Education is the backbone of a nation; the world in which we live today is comprised of diverse people where educators face complex-tasks in educating (Salam et al., 2014). Planned interventional education programs have been shown to provide a positive impact on outcomes (Salam, 2010).

A planned and integrated breast self examination educational campaign through collaboration among the policy makers, health care providers and mass media will definitely promote a sustainable culture of BSE knowledge, beliefs and practices (Salaudeen et al., 2009). Therefore, policy makers and health care professionals should give due importance on BSE as an early and most cost effective tool for detection of breast cancer and thereby to promote a healthy life.

\section{CONCLUSIONS}

Participants' knowledge on BSE was found satisfactory except for the timing of BSE in relation to menstruation and position to perform BSE. Although participants were motivated to perform BSE, they did not believe that they were susceptible to breast diseases. A good number of participants started BSE practices at the age of 19 years but their frequency and timing for BSE was not satisfactory.

Their practice rate was low in spite of having very good knowledge on technique. These data imply that teachers in Baguio city in Philippine need more educational intervention on breast cancer and its early detection particularly by BSE. By knowing how to do thorough BSE, teachers and women in general will be able to identify breast cancer at the initial stages. This in turn may help to eventually decrease the number of premature breast cancer deaths in developing countries such as Philippines.

Breast cancer and breast-self-examination awareness campaign programs targeted at younger women are suggested to remove fear and misperceptions on BSE and thereby improve breast cancer prevention. Policymakers and healthcare professionals should implement integrated breast cancer and BSE awareness campaign to promote BSE as an early and cost-effective breast cancer screening tool.

\section{CONFLICT OF INTEREST}

The authors declare that they have no conflict of interests.

\section{REFERENCES}

Adibi A, Golshahi M, Sirus M, and Kazemi K. Breast cancer screening: Evidence of the effect of adjunct ultrasound screening in women with unilateral mammography-negative dense breasts. J Res Med Sci, 2015; 20(3):228-232.

Agboola AOJ, Deji-Agboola AM, Oritogun KS, Musa AA, Oyebadejo TY, Ayoade BA. Knowledge, Attitude and Practice of Breast Self-Examination in Female Health Workers in Olabisi Onabanjo University Teaching Hospital, Sagamu, Nigeria. IMJ, $2009 ; 8$ (1):5-10.

Agwu UM, Ajaero, EP, Ezenwelu CN, Agbo CJ, Ejikeme BN. Knowledge, attitude and practice of breast self-examination among nurses in Ebonyi State University Teaching Hospital, Abakaliki. Ebonyi Med J, 2007. 6:44-47.

Al-Azmy SF, Alkhabbaz A, Almutawa HA, Ismaiel AE, Makboul G, El-Shazly MK. Practicing breast self-examination among women attending primary health care in Kuwait. Alexandria J Medicine, 2013; 49:281-286.

Alegre A, Ramo LV. Breast Cancer Incidence Highest among Filipinas in SEA. Northern Dispatch, 2007; VII(6).

American Cancer Society (ACS). Breast Cancer Facts \& Figures 2005-2006. American Cancer Society, 2005. Inc Atlanta.

Anderson BO, Braun S, Carlson RW, Gralow JR, Lagios MD, Lehman C, Schwartsmann G, Vargas HI. Overview of breast health care guidelines for countries with limited resources. Breast J, 2003; 9:S42-50. doi: 10.1046/j.1524-4741.9.s2.3.x.

Budden L. Student nurses' breast self-examination health beliefs, attitudes, knowledge, and performance during the first year of a preregistration degree program. Cancer Nursing, 1999; 22(6):430-437.

Canadian Cancer Society (CCS). National Cancer Institute of Canada. Canadian Cancer Statistics, 2005. Toronto.

Champion VL, Scott CR. Reliability and validity of breast cancer screening Belie Scales in African American women. Nursing Research, 1997; 46:331-337. doi: 10.1097/00006199-199711000-00006.

Champion VL. Development of a benefits and barriers scale for mammography utilization.

Cancer Nursing, 1995; 18:53-59.

Champion VL. Instrument refinement for breast cancer screening behaviors. Nursing Research, 1993; 42:139-143.

Chong PN, Krishnan M, Hong CY, Swash TS. Knowledge and practice of breast cancer screening amongst public health nurses in Singapore. Singapore Med J, 2002; 43:509-516.

Demirkiran F, Balkaya NA, Memis S, Turk G, Ozvurmaz S, Tuncyurek P. How do nurses and teachers perform breast self-examination: Are they reliable sources of information? BMC Public Health, 2007; 7:96.

Devi R, Singh MM, Kumar R, Walia I. An effective manual on breast self-examination. World Health Forum, 1998; 19:388-389.

Doshi D, Reddy BS, Kulkarni S, Karunakar P. Breast Selfexamination: Knowledge, Attitude, and Practice among Female Dental Students in Hyderabad City, India. Indian J Palliat Care, 2012; 18(1):68 73. doi:10.4103/0973-1075.97476.

Feyzabadi VY, Emami M, Mehrolhassani MH. Health information system in primary health care: The challenges and barriers from local providers' perspective of an area in Iran. Int J Prev Med, 2015; 6:57. doi:10.4103/2008-7802.160056

Haji-Mahmoodi M, Montazeri A, Jarvandi S, Ebrahimi M, Haghigat S, Harirchi I. Breast self-examination: knowledge, attitudes, and practice among female health care in Tahran. Iran Breast J, 2002;8:222-25.

Jafari M, Rafiei H, Nassehi A, Soleimani F, Arab M, Noormohammadi MR. Caring for dying patients: Attitude of nursing students and effects of education. Indian J Palliat Care, 2015; 21:192-197. 
Jarvandi S, Montazeri A, Harirchi I, Kazemnejad A. Beliefs and behaviours of Iranian teachers toward early detection of breast cancer and breast self-examination. Public Health, 2002; 116:245-249. doi: 10.1038/sj.ph.1900854.

Jemal A, Siegel R, Ward E, Murray T, Xu J, Smigal C, Thun MJ. Cancer statistics 2006. CA. A Cancer J Clin, 2005; 56(2):106-130.

Karimian Z, Mehran N, Haddad Z. The Assessment of Knowledge, Attitude and Behavior of Women in Qom Toward Breast cancer Screening Methods 2009. Res J Med Sci, 2010; 4(3):116-118.

Montazeri A, Vahdaninia M, Harirchi I, Harirchi AM, Sajadian A, Khaleghi F, Ebrahimi M, Haghighat S, and Jarvandi S. Breast cancer in Iran: Need for greater women awareness of warning signs and effective screening methods. Asia Pac Fam Med, 2008; 7(1):6.

Odusanya OO, Tayo OO. Breast cancer knowledge, attitudes and practice among nurses in Lagos, Nigeria. Acta Oncologia, 2001; 40:844-848. doi: 10.1080/02841860152703472.

Parkin DM, Bray F, Ferlay J, Pisani P. Global cancer statistics, 2002. CA. Cancer J Clin, 2005; 55:74-108.

Parkin DM, Bray FI, Devesa SS. Cancer burden in the year 2000:the global picture. Eur J Cancer, 2001; 37(suppl. 8):S4-66.

Philip J, Harris WG, Flaherty C, Joslin CA. Clinical measures to assess the practice and efficiency of breast self-examination. Cancer, 1986; 58:973-977.

Puri S, Mangat C, Bhatia V, Kalia M, Sehgal A, \& Kaur A. Awareness of Risk Factors and Aspects of Breast Cancer Among North Indian Women. The Int J Health, 2008; 8(2).

Rizwan MM, Saadullah M. Lack of awareness about breast cancer and its screening in developing countries. Indian J Cancer, 2009; 46:252-253.

Rutledge DN, Barsevick A, Knobf MT, Bookbinder M. Bresat cancer detection: of women from Pennysylvania. Oncol Nurs Forum, 2001; 28(6):1032-1040.

Salam A, Akram A, Bujang SM, Yaman MN, Kamarudin MA, Siraj HH, Mohamad N. Educational Environment in a Multicultural Society to Meet the Challenges of Diversity. J App Pharm Sci, 2014; 4 (09): 110-113.

Salam A. Educational program for patients with type-1 diabetes mellitus receiving free monthly supplies of insulin improves knowledge and attitude, but not adherence. Int J Diab Dev Ctries, 2010; 30:105.
Salaudeen AG, Akandem TM, Musa OI. Practice of Breast Selfexamination among Young Adults in Tertiary Institutions in Ilorin, North Central Nigeria. Res J Med Sci, 2009; 3(1):31-35.

Sharma PK, Ganguly E, Nagda D, Kamaraju T. Knowledge, attitude and preventive practices of South Indian women towards breast cancer. The Health Agenda, 2013; 1 (1):16-22

Smith EM, Francis AM, Polissar L. The effect of breast selfexam practices and physician examinations on extent of disease at diagnosis. Prev Med, 1980; 9:409-417.

doi: 10.1016/0091-7435(80)90235-2.

Tazhibi M, Dehkordi ZF, and Babazadeh S. Trends in breast cancer incidence rates by age and tumor characteristics of women in the city of Isfahan for the period 2001-2010: An application of join point analysis. J Res Med Sci, 2014; 19(4):319-325.

Yakubu AA, Gadanya MA, Sheshe AA. Knowledge, attitude, and practice of breast self-examination among female nurses in Aminu Kano teaching hospital, Kano, Nigeria. Niger J Basic Clin Sci, 2014; 11:85-88.

Zisun Kim, Sun Young Min, Chan Seok Yoon, Kyu-Won Jung, Beom Seok Ko, Eunyoung Kang, Seok Jin Nam, Seokwon Lee, Min Hee Hur, Korean Breast Cancer Society. The Basic Facts of Korean Breast Cancer in 2012: Results from a Nationwide Survey and Breast Cancer Registry Database. J Breast Cancer, 2015; 18(2):103-111. doi:org/10.4048/jbc.2015.18.2.103.

\section{How to cite this article:}

Roy Rillera Marzo, Abdus Salam. Teachers' Knowledge, Beliefs and Practices of Breast Self-Examination in a City of Philippine: A Most Cost-Effective Tool for Early Detection of Breast Cancer. J App Pharm Sci, 2016; 6 (02): 016-021. 